\title{
LA PAIX
}

DU 9 JANVIER 1478 .

BNTRE

\section{LOUIS XI ET LA RÉPUBLIQUE DE VENISE}

Les rapports de Louis XI avec Venise furent assez cordiaux jusque vers 1465 ou $1468^{1}$ : il n'y avait pas entre eux de traité, mais une entente tacite et réciproque, profitable surtout au gouvernement de Venise, parce qu'elle ouvrait à Montpellier et à Aigues-Mortes des débouchés moins importants, il est vrai, qu'a Bruges et à Londres, cependant fort considérables pour les marchandises que ses nationaux rapportaient du Levant². Les premières difficultés paraissent devoir être attribuées à Louis XI. Vers 1467, il interdit l'importation en France des épices sous pavillon étranger ${ }^{3}$; cette mesure, qui atteignait principalement les Vénitiens et devait, au dire du chancelier Doriole, leur faire subir une perte de deux à trois cent mille écus par an ${ }^{4}$, eut pour conséquence de jeter la Seigneurie dans les bras de Charles le Téméraire : elle lui envoya un ambassadeur nommé Antoine Dandolo ${ }^{5}$

1. Nous n'insistons pas sur les relations de Venise avec la France antérieurement à 1469, nous réservant de les traiter en détail dans l'ouvrage que nous préparons sur les relations de la France avec Venise an $x \nabla^{\bullet}$ sieccle, et dont l'étude qui suit forme un chapitre.

2. Germain, Histoire du commerce de Montpellier, Montpellier, 1861, t. I, p. 175, et Mas Latrie, Commerce et expéditions militaires de la France et de Venise au moyen áge (Collection des documents inédits. Melanges, 2• série, t. III, Paris, 1880), p. 195.

3. Voy. Pigeonneau, Hist. du commerce de la France, Paris, 1887, t. I, p. 415.

4. Id., ibid., p. 416.

5. V. ses instractions du 23 octobre 1467. Arch. de Venise, Senato. Deliberazioni secrete, t. XXIII, fol. 78 . 